\title{
Covid-19: risk factors for severe disease and death
}

\author{
A long list is emerging from largely unadjusted analyses, with age near the top
}

\section{Rachel E Jordan reader in epidemiology and primary care, Peymane Adab professor of chronic disease epidemiology and public health, K K Cheng professor of public health and primary care}

Institute of Applied Health Research, College of Medical and Dental Sciences, University of Birmingham, Edgbaston, Birmingham B15 2TT, UK

\begin{abstract}
As the covid-19 pandemic accelerates, governments are warning people at high risk to be particularly stringent in observing social distancing measures because if they become ill they are more likely to need critical care including ventilation, and to die. ${ }^{1}$ Most data on covid-19 are from China, and although most confirmed cases have been classified as mild or moderate, $14 \%$ are severe and $5 \%$ critical. $^{2}$ Case fatality rates are difficult to assess with certainty but could be as high as $1 \%,{ }^{34}$ which is much greater than seasonal influenza at about $0.1 \%$.

Up to $25 \%$ of people in the United Kingdom are designated high risk-including all adults aged over 70 and those with underlying health conditions such as respiratory and cardiovascular disease, and cancer. ${ }^{5}$ Strict restrictions are now in place for everyone, reducing movement outside the home to an absolute minimum, except for essential workers. ${ }^{6}$ These measures will be in place for weeks, possibly months. Among vulnerable groups including older adults, such severe restrictions are likely to lead to further loneliness, isolation, and loss of mental and physical function.
\end{abstract}

Evidence is rapidly accumulating about covid-19 and its causal agent SARS-CoV-2. In a linked study, Chen and colleagues (doi:10.1136/bmj.m1091) report on the first 799 people with the disease who were admitted to the isolation ward of a hospital in Wuhan, China, assigned for patients with severe or critical covid-19. ${ }^{7}$ The authors compared the characteristics of 113 (14.4\%) patients who have died so far with those of 161 patients who recovered, finding that those who died were on average 17 years older (with no deaths among those aged under 40 and $16.8 \%$ of deaths among those aged $40-60$ ), more likely to be male, and more likely to have a comorbidity such as hypertension, diabetes, cardiovascular disease, or chronic lung disease.

These results are similar to many other case series from China. ${ }^{28-11}$ The largest so far is the China Center for Disease Control and Prevention's report of 44000 people with laboratory confirmed covid-19. Older age, cardiovascular disease, diabetes, chronic respiratory disease, hypertension, and cancer were all associated with an increased risk of death. ${ }^{2}$ A meta-analysis of eight studies including 46248 patients with laboratory confirmed covid-19 indicated that those with the most severe disease were more likely to have hypertension (odds ratio 2.36 (95\% confidence interval 1.46 to 3.83$)$ ), respiratory disease (2.46 (1.76 to 3.44$)$ ), and cardiovascular disease (3.42 (1.88 to 6.22$)$ ). ${ }^{12}$

In other studies, obesity and smoking were associated with increased risks. ${ }^{1011}$ In Italy, higher risks have also been reported in men than in women, ${ }^{13}$ which could be partly due to their higher smoking rates and subsequent comorbidities.

However, the relative importance of different underlying health conditions is unclear, owing to inadequate adjustment for important confounding factors such as age, sex, and smoking status; insufficient follow-up ${ }^{14}$; and likely under-reporting of pre-existing conditions. In China, health records are often incomplete or inaccurate and chronic conditions are underdiagnosed. ${ }^{1516}$

Even when smoking status is reported, data appear incomplete. Only $7 \%$ of the population in Chen and colleagues' study identified as ever smokers (defined as $\geq 30$ pack years), whereas smoking prevalence among Chinese men is over $60 \% .{ }^{17}$ Finally, these studies are mainly among those patients at the highest risk, admitted to hospital with full testing. Findings might not apply to the general population.

As yet, there are no good data on how the risks associated with underlying comorbidities might vary in different population groups or settings. Unlike other viruses, symptomatic infections are uncommon in children and, although not resistant, ${ }^{18}$ children are at low risk of severe disease. Based on current data, the mean case fatality rate for adults aged under 60 is estimated to be less than $0.2 \%$, compared with $9.3 \%$ in those aged over $80{ }^{4}$ Even if comorbidities increased mortality risk by five times, risk would remain lower for younger people than for most older adults.

As we await more data, government guidance draws on knowledge of risk factors for other similar infections such as influenza, severe acute respiratory syndrome, and Middle East respiratory syndrome. Although younger people appear generally at lower risk, everyone must adhere to government restrictions to protect the millions of people at higher risk due to age or serious comorbidities. 
In order to minimise future social and economic disruption, high quality data at the population level are urgently needed-as soon as a reliable test for past infection becomes available. All further studies of both past and current infections must include complete and accurate data on all potential risk factors; ideally through electronic healthcare records. Most importantly, data must be gathered and pooled across countries, so we can optimise our understanding.

Competing interests: The BMJ has judged that there are no disqualifying financial ties to commercial companies. The authors declare the following other interests: REJ has given one off advice to Boehringer Ingelheim unrelated to this topic. The BMJ policy on financial interests is here: https://www.bmj.com/sites/default/files/ attachments/resources/2016/03/16-current-bmj-education-coi-form.pdf. Provenance and peer review: Commissioned; not peer reviewed.

1 Public Health England. Guidance on social distancing for everyone in the UK. 2020. https: //www.gov.uk/government/publications/covid-19-guidance-on-social-distancing-and-forvulnerable-people/guidance-on-social-distancing-for-everyone-in-the-uk-and-protectingolder-people-and-vulnerable-adults

2 Wu Z, McGoogan JM. Characteristics of and important lessons from the coronavirus disease 2019 (COVID-19) outbreak in China: summary of a report of 72314 cases from the Chinese Center for Disease Control and Prevention. JAMA 2020. 10.1001/jama.2020.2648 32091533

3 Wu JT, Leung K, Bushman M, etal . Estimating clinical severity of COVID-19 from the transmission dynamics in Wuhan, China. Nat Med 2020. 10.1038/s41591-020-0822-7.

4 Ferguson NM, Laydon D, Nedjati-Gilani G, et al, on behalf of the Imperial College COVID-19 Response Team. Impact of non-pharmaceutical interventions (NPIs) to reduce COVID19 mortality and healthcare demand. https://www.imperial.ac.uk/media/imperialcollege/medicine/sph/ide/gida-fellowships/Imperial-College-COVID19-NPI-modelling-1603-2020.pdf

5 Public Health England. Seasonal influenza vaccine uptake in GP patients: winter season 2018 to 2019. https://www.gov.uk/government/statistics/seasonal-flu-vaccine-uptake-ingp-patients-winter-2018-to-2019.
6 Gov.uk. New rules on staying at home and away from others. 2020. https://assets. publishing.service.gov.uk/government/uploads/system/uploads/attachment_data/file/ 874742/Full_guidance_on_staying_at_home_and_away_from_others_1_.pdf

7 Chen T, Wu D, Chen H, etal . Clinical characteristics of 113 deceased patients with coronavirus disease 2019: retrospective study. BMJ 2020;368:m1091.

8 Zhou F, Yu T, Du R, etal . Clinical course and risk factors for mortality of adult inpatients with COVID-19 in Wuhan, China: a retrospective cohort study. Lancet 2020. 10.1016/S0140-6736(20)30566-3 32171076

9 Guan WJ, Ni ZY, Hu Y, Liang WH, Ou CQ, He JX, et al. Clinical characteristics of 2019 novel coronavirus infection in China. medRxiv [Preprint] 2020. .

10 Huang $R$, Zhu L, Xue L, et al. Clinical findings of patients with coronavirus disease 2019 in Jiangsu Province, China: a retrospective, multi-center study. 2020. https://ssrn.com/ abstract $=3548785$

11 Wang D, Hu B, Hu C, etal . Clinical characteristics of 138 hospitalized patients with 2019 Novel Coronavirus-Infected pneumonia in Wuhan, China. JAMA 2020;323:1061-9. 10.1001/jama.2020.1585 32031570

12 Yang J, Zheng Y, Gou X, etal . Prevalence of comorbidities in the novel Wuhan coronavirus (COVID-19) infection: a systematic review and meta-analysis. Int $J$ Infect Dis 2020;S1201-9712(20)30136-3. 10.1016/j.jijid.2020.03.01732173574

13 Livingston E, Bucher K. Coronavirus Disease 2019 (COVID-19) in Italy. JAMA 2020 10.1001/jama.2020.4344. 32181795

14 Kobayashi T, Jung SM, Linton NM, etal . Communicating the risk of death from novel coronavirus disease (COVID-19). J Clin Med 2020;9:580. 10.3390/jcm9020580 32098019

15 Fang L, Gao P, Bao H, etal . Chronic obstructive pulmonary disease in China: a nationwide prevalence study. Lancet Respir Med 2018;6:421-30. 10.1016/S2213-2600(18)30103-6. 29650407

16 Li D, Lv J, Liu F, etal . Hypertension burden and control in mainland China: Analysis of nationwide data 2003-2012. Int J Cardiol 2015;184:637-44. 10.1016/j.jijcard.2015.03.045 25771229

17 Liu S, Zhang M, Yang L, etal . Prevalence and patterns of tobacco smoking among Chinese adult men and women: findings of the 2010 national smoking survey. $J$ Epidemiol Community Health 2017;71:154-61. 10.1136/jech-2016-207805 27660401

18 Dong Y, Mo X, Hu Y, etal . Epidemiological characteristics of 2143 pediatric patients with 2019 coronavirus disease in China. Pediatrics 2020:e20200702. 10.1542/peds.2020-0702 32179660

Published by the BMJ Publishing Group Limited. For permission to use (where not already granted under a licence) please go to http://group.bmj.com/group/rights-licensing/ permissions 